\title{
Systemic hypothermia following spinal cord compression injury in the rat: axonal changes studied by $\beta$-APP, ubiquitin, and PGP 9.5 immunohistochemistry
}

\author{
H Westergren*,1, WR Yu², M Farooque ${ }^{2}$, A Holtz $^{1}$ and Y Olsson ${ }^{2}$ \\ ${ }^{1}$ Section of Neurosurgery, Department of Neuroscience, Uppsala University, Sweden; ${ }^{2}$ Research Group of \\ Neuropathology, Department of Genetics and Pathology, Uppsala University, Sweden
}

\begin{abstract}
Study Design: Systemic hypothermia exerts neuroprotective effects in experimental ischemic CNS models caused by vascular occlusions. Recent experimental and clinical studies have also demonstrated beneficial effects of hypothermic treatment following brain trauma.

Objectives: The present study addresses the question as to whether systemic hypothermia has similar protective qualities following severe spinal cord compression trauma using $\beta$-APP-, ubiquitin-, and PGP-9.5-immunohistochemistry combined with the ABC complex method as markers to identify axonal changes.

Methods: Fifteen rats were randomized into three equally large groups and sustained to either thoracic laminectomy or to severe spinal cord compression trauma of the Th $8-9$ segments. The non-trauma group contained laminectomized animals submitted to a hypothermic procedure in which the core temperature was reduced from 38 to $30^{\circ} \mathrm{C}$. The two trauma groups were either submitted to the same hypothermic procedure or kept normothermic during the corresponding time. All animals were sacrificed $24 \mathrm{~h}$ following the surgical procedure.

Results: In the hypothermic non-trauma group no axonal changes were seen. The number of abnormal axons, as indicated by accumulation of immunoreactive material in enlarged axons, was lower in the peri-injury zones of the hypothermic trauma group than in the normothermic trauma group. This difference was most obvious in the cranial peri-injury zones. No differences were seen between the groups in the trauma zones.

Conclusions: This study demonstrates reduced axonal swelling in the peri-injury zones of spinal cord injured rats treated with systemic hypothermia. These changes could either indicate neuroprotective effects of the hypothermic treatment, or be results of reduced axonal transport or protein synthesis. To evaluate the clinical importance of our findings, further studies including reliable outcome measures of the animals must be performed.
\end{abstract}

Keywords: hypothermia; spinal cord trauma; $\beta$-APP-, ubiquitin-, PGP-9.5-immunohistochemistry

\section{Introduction}

Trauma to the spinal cord can lead to a diversity of neurological deficits, depending on the site and size of the injury. These deficits can be permanent or transient due to the degree of axonal injury. The development of specialized, multidisciplinary spinal units has brought forward a general improvement in the care of spinal cord injured patients. ${ }^{1,2}$ In spite of this a deterioration of the patients' neurological symptoms is still often seen during the first days following trauma. ${ }^{3}$ It is

*Correspondence: H Westergren, Department of Neurosurgery, University Hospital, SE-751 85 Uppsala, Sweden generally believed that the mechanical trauma initiates secondary injuries ${ }^{4,5}$ caused, for instance, by excitotoxic factors, ${ }^{6}$ free radicals, ${ }^{7}$ and vascular changes ${ }^{8}$ leading to edema, degeneration of nerve cells, axonal lesions, apoptosis of local neurons ${ }^{9,10}$ and activation of glial cells. ${ }^{11,12}$

Experimental research has demonstrated some pharmacological means of reducing the extent of the secondary injuries. ${ }^{13}$ Treatment with high doses of methylprednisolone has been brought into clinical practice. $^{14}$ Today several studies have reported progress regarding axonal regeneration ${ }^{15-17}$ and transplantation. ${ }^{18,19}$ Therefore, it seems important to seek and evaluate new methods of reducing the effects 
of secondary injuries afflicting axons of the spinal cord and thereby optimize prerequisites for an improved functional outcome.

Axonal injury can result in either transient depolarization, focal loss of axonal transport or total disconnection, depending on the strain applied to the single axon. ${ }^{20}$ Arrested axonal transport will result in an accumulation of membranous organelles and proteins at the site of injury, which can lead to axonal swelling and aggravation of the axonal damage. ${ }^{20,21}$ Such injured axons are often referred to as 'retraction balls' or 'swollen axons'. ${ }^{22}$ During the last few years several very useful immunohistochemical methods have been introduced to identify protein components in the axonal swellings, like $\beta$-amyloid protein precursor ( $\beta$-APP), ${ }^{23}$ ubiquitin ${ }^{24,25}$ and protein gene product 9.5 (PGP 9.5). ${ }^{26-28}$

In view of the importance of axonal integrity for the spinal cord function we have now addressed the question as to whether systemic hypothermia exerts protective effects on the longitudinal axons following spinal cord compression trauma in the rat. By using the same model of spinal cord compression trauma in the rat we have previously reported beneficial effects of systemic hypothermia on glial cell activation ${ }^{29}$ and the formation of edema. ${ }^{30}$ Moreover it is known from previous studies that hypothermia exerts neuroprotective effects on the spinal cord following ischemia caused by vascular occlusion. ${ }^{31,32}$ However, the effect following neurotrauma has not been fully evaluated to date. ${ }^{33-35}$

\section{Materials and methods}

\section{Animal preparation}

Fifteen male Sprague-Dawley rats with a mean body weight of $387 \pm 37 \mathrm{~g}$ were used. Food and water were provided ad libitum before the experiments. The rats were kept at a temperature of $20^{\circ} \mathrm{C}$ controlled thermostatically and exposed to alternate light and dark periods of $12 \mathrm{~h}$. The study was approved by the Uppsala Ethical Committee for Animal Research. The animals derived from one previous investigation in which our experimental model of hypothermia has been presented together with the results of simulta- neous temperature recordings in the esophagus, the rectum, the epidural space and the spinal cord parenchyma. ${ }^{36}$

The animals were anesthetized by a subcutaneous (sc) bolus injection of Hypnorm ${ }^{\circledR} /$ Dormicum ${ }^{\circledR}$ (1 part Hypnorm ${ }^{\circledR}+1$ part Dormicum ${ }^{\circledR}+2$ parts distilled water: $1.5-2.0 \mathrm{ml} / \mathrm{kg}$ ). Additional small doses were administered sc at regular intervals throughout the experiment. A catheter (PE 60) was inserted into the right carotid artery for sampling and blood pressure monitoring. A tracheotomy was performed, after which the animals were connected to a small-animal ventilator (Braun, Melsungen AG, Germany), and the blood gases were adjusted to $\mathrm{PCO}_{2} 4.5-5.5 \mathrm{kPa}$ and $\mathrm{PO}_{2} 9-19 \mathrm{kPa}$.

After the experiment the animals were carefully dried and put in single cages under the same conditions as described above.

\section{Experimental groups}

The immunohistochemically analyzed samples derived from three groups (Table 1). The first group contained animals laminectomized and submitted to the hypothermic procedure described below (hypothermic non-trauma group). The animals in the two trauma groups were exposed to severe spinal cord compression followed by insertion of an intramedullary temperature probe into the spinal cord contusions. These animals were then either submitted to the hypothermic procedure described below (hypothermic trauma group) or were kept normothermic during the corresponding time (normothermic trauma group). All animals were sacrificed $24 \mathrm{~h}$ following the surgical procedure.

\section{Spinal cord compression injury}

We used a model providing extradural compression of the spinal cord from the dorsal side. ${ }^{37}$ Briefly, the laminae of Th 7 and Th 8 vertebrae, which overlie the Th 8 and Th 9 segments of the spinal cord, were removed, leaving the dura intact. The animals were placed in a stereotaxic apparatus with two adjustable forceps applied to the spinous processes of vertebrae proximal and distal to the laminectomy in order to

Table 1 The experimental groups

\begin{tabular}{lclr}
\hline Group & $\begin{array}{c}\text { No. of } \\
\text { animals }\end{array}$ & $\begin{array}{l}\text { Surgical } \\
\text { procedure }\end{array}$ & Treatment \\
\hline $\begin{array}{l}\text { Hypothermic non-trauma group } \\
\text { Hypothermic trauma group }\end{array}$ & 5 & $\begin{array}{l}\text { Laminectomy Th 7-8 } \\
\text { Laminectomy Th 7-8 } \\
\text { Compression trauma } \\
\text { sacrifice }\end{array}$ \\
Normothermic trauma group & 5 & $\begin{array}{l}\text { Intramedullary temperature recording } \\
\text { Laminectomy Th 7-8 } \\
\text { Compression trauma } \\
\text { Intramedullary temperature recording }\end{array}$ & $\begin{array}{l}\text { Hypothermic procedure } \\
\text { Hypothermic procedure }\end{array}$ \\
$24 \mathrm{~h}$ & Normothermic procedure $\quad 24 \mathrm{~h}$ \\
\hline
\end{tabular}


stabilize the spine (Figure 1). A weight of $50 \mathrm{~g}$ was applied on the intact dura, for a period of $5 \mathrm{~min}$, using a curved rectangular plate $(2.2 \times 5 \mathrm{~mm})$. This trauma has been shown to cause a hemorrhagic necrosis in the injury zone (Th 8-9) and less pronounced changes in the cranial (Th 7) and the caudal (Th 10) peri-injury zones. $^{37}$

\section{Temperature recordings}

Two Physitemps thermometers (Thermalert TH-5 and TH-8, Physitemps Instruments Inc.; Clifton, NJ, USA) were used. The sensitivity of the reading was $0.1^{\circ} \mathrm{C}$. The calibration was checked against a mercury thermometer in a water-filled test tube. A thermocouple with a sealed tip $0.64 \mathrm{~mm}$ in diameter (IT-18) was inserted in the esophagus to the heart level 5$6 \mathrm{~cm}$ from the teeth. In the trauma groups a thermocouple with an unsealed tip $0.23 \mathrm{~mm}$ in diameter (IT-1E) was inserted through a heat isolated glass tube into the spinal cord contusion using a micromanipulator attached to a specially designed stereotaxic frame. The thermocouple was inserted about $3 \mathrm{~mm}$ obliquely into the spinal cord contusion in the mid-line of the spinal cord.

\section{Hypothermic procedure}

The core temperature recorded in the esophagus was reduced from 38 to $30^{\circ} \mathrm{C}$ by wetting the animals with a $20 \%$ ethanol/water solution in room temperature $\left(20^{\circ} \mathrm{C}\right)$. The core temperature was then kept as close as possible to $30^{\circ} \mathrm{C}$ for 20 min after which the animals were rewarmed using a heating fan connected to a box measuring $45 \times 33 \times 28 \mathrm{~cm}$, which covered the entire stereotaxic device. The animals were finally decannulated after a 20 min steady state with core temperature as close as possible to $38^{\circ} \mathrm{C}$. The temperature in the spinal cord contusion was recorded from the termination of the compression trauma to the end of the experiment.

\section{Normothermic procedure}

The core temperature recorded in the esophagus was kept as close as possible to $38^{\circ} \mathrm{C}$ for $90 \mathrm{~min}$, which corresponds to the experimental time in the other groups. The temperature in the spinal cord contusion was recorded from the termination of the compression trauma to the end of the experiment.

\section{Physiological parameters}

Physiological parameters such as blood gases and blood (B) glucose, sodium, potassium and calcium were measured in the hypothermic groups as follows: (a) directly after preparation (ie at $38^{\circ} \mathrm{C}$ prior to the cooling procedure), (b) during hypothermia (steady state $30^{\circ} \mathrm{C}$ ) and (c) during normothermia (steady state $38^{\circ} \mathrm{C}$ ). In the normothermic group the same parameters were measured (a) before, (b) 45 and (c) $90 \mathrm{~min}$ after the trauma. The blood samples were analyzed in a blood gas/electrolyte analyzer (IL 1640; ILS Laboratories, Scandinavia AB, Stockholm, Sweden). The temperature calibration was maintained at $37^{\circ} \mathrm{C}$.

\section{Morphological methods}

The animals were sacrificed $24 \mathrm{~h}$ after the initial surgery using the same anesthetic procedure. The chests were rapidly opened, followed by a perfusion through the heart with $200 \mathrm{ml}$ of phosphate buffer solution (PBS, pH 7.4) followed in turn by $200 \mathrm{ml}$ of $4 \%$ formaldehyde solution in the same buffer at $100 \mathrm{mmHg}$. The spinal cord samples from Th 7, Th $8-9$ and Th 10 segments were kept in fixative overnight and dehydrated. Transverse blocks were embedded in paraffin. Sections measuring $5 \mu \mathrm{m}$ were stained with hematoxylin and eosin and by immunohistochemistry to display the swollen axons with the $\beta$ APP, ubiquitin, and PGP 9.5-immunomethods.

The immunohistochemistry procedure for $\beta$-APP, ${ }^{21}$ ubiquitin $^{38}$ and PGP $9.5^{28}$ is described in detail

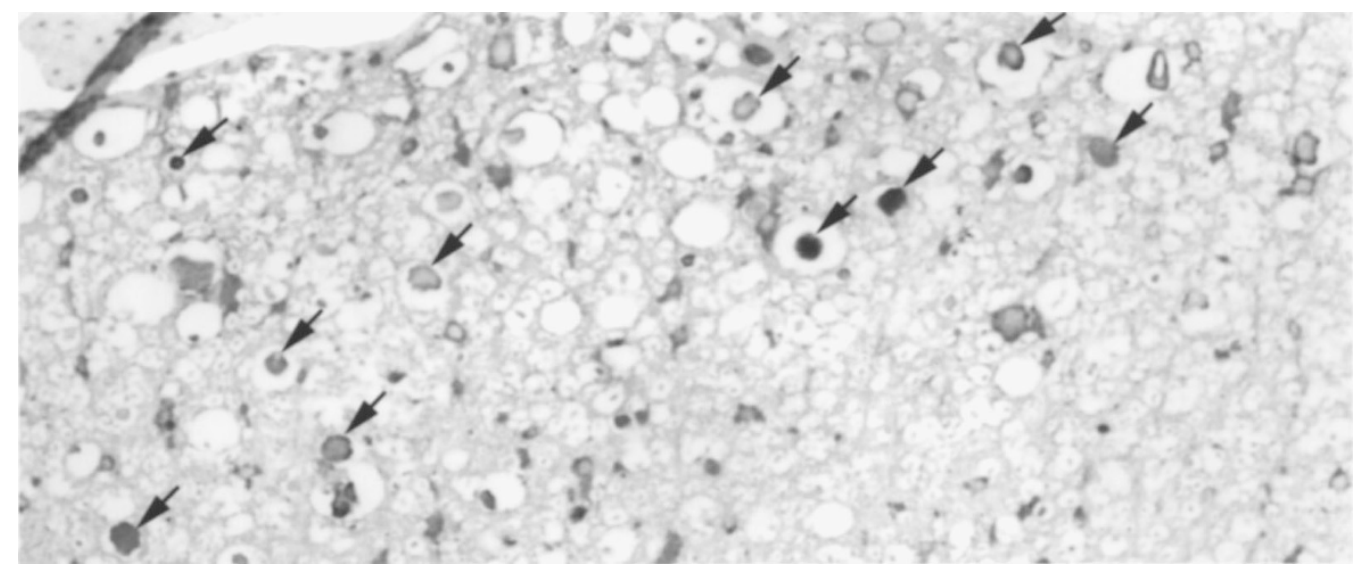

Figure 1 Transverse section from one normothermic traumatized rat stained for $\beta$-APP. Arrows indicate numerous abnormal, often expanded and intensely immunoreactive axons 
elsewhere. Briefly, all samples were deparaffinized, and the $\beta$-APP and ubiquitin samples were treated in a microwave oven in citrate buffer $\mathrm{pH} 6.0$ for $10 \mathrm{~min}$ to unmask antigenic sites. All samples were then exposed to $1 \%$ hydrogen peroxide in PBS to block endogenous peroxidase activity. The ubiquitin samples were exposed to $20 \%$ normal rabbit serum in PBS buffer for $30 \mathrm{~min}$ and the PGP 9.5 samples, to pure normal swine serum for $30 \mathrm{~min}$. All samples were then incubated with their respective antibodies overnight.

The following antibodies were used: $\beta$-APP, a monoclonal antibody against the $\mathrm{NH}_{2}$-terminal part of the $\beta$-APP antigen (Boeringer Mannheim Biochemical clone 22C11); for ubiquitin a monoclonal antibody against ubiquitin (mAb 1510 Chemicon, Temecula, CA, USA); and for PGP 9.5, rabbit antiserum against human PGP 9.5 (code no. RA 95101, Chemicon, Temecula, CA, USA). The $\beta$-APP and ubiquitin samples were then exposed to rabbit-anti mouse $\mathrm{IgG}$, and the PGP 9.5 samples, to swine anti-rabbit IgG in $20 \%$ normal swine serum, for $30 \mathrm{~min}$. Finally, all reaction products were visualized using the avidin-biotin-peroxidase complex (ABC) method with 3.3-diaminobezidine tetrahydro-chloride as chromogen (Vectastain Elite Kit, Vector Laboratories, Burlingame, CA, USA). To intensify the reaction product, the nickel enhancement procedure combined with the glucose-glucose oxidase method was applied. ${ }^{39-41}$

\section{Morphological analysis}

To analyze the results of the immunostainings, one section from each of the three separate immunohistochemical analyses was taken from three parts of the spinal cord in every animal: the cranial peri-injury zone (T 7), injury zone (Th 8-9) and caudal peri-injury zone (T 10). The analysis was made by ocular inspection in a light microscope by two independent people. The number of swollen axons observed in each section was indicated as follows: no swollen axons $(0-$ $1)$, few swollen axons $(2-10)$, and frequent swollen axons $(>10)$.

A computer program IMP (Centre of Image Analysis, Uppsala University, Sweden) was used to measure the area of the whole spinal cord crosssections.

\section{Data evaluation}

The physiological parameters and the spinal cord cross-sections were statistically processed using the computer program Statview 4.01 from Abacus Concepts. For comparison of multiple means between groups, factorial analysis of variance was used. Fisher's protected least squares difference (PLSD) test was performed for post hoc testing. Values in Figures are given as the mean $\pm \mathrm{SD}$. Differences with a $P$-value $<0.05$ were considered significant.

\section{Results}

Physiological parameters

Briefly, the electrolytes and blood gases were stable in the normothermic trauma group (Table 2). In the hypothermic groups significant changes were recorded in B-potassium during the rewarming procedure and in $\mathrm{pH}$ and $\mathrm{PO}_{2}$ during hypothermia.

The mean systolic blood pressure in all animals was $110 \pm 12 \mathrm{mmHg}$ at the end of the surgical procedure and $105 \pm 14 \mathrm{mmHg}$ at the end of the experiment. No significant differences in blood pressure were found between the groups. The blood pressure was not changed by the hypothermic procedure.

There were no significant differences in the body weight or in the duration of the preparation procedure between the groups.

\section{Recorded temperatures and hypothermic procedure}

The mean cooling and rewarming times, together with the mean temperatures for the hypo- and normothermic steady states, are presented in Table 3. The temperatures in the spinal cord contusions were significantly lower compared to the esophageal temperatures during the normothermic steady state, independent of previous hypothermic procedure or constant normothermia. No such difference was recorded during the hypothermic steady states.

\section{Macroscopic and general light microscopic findings}

The spinal cords in rats from the hypothermic nontrauma group did not show any macroscopic changes. With the exception of a few condensed nerve cell bodies, microscopy of sections from the Th 7-10 segments stained with hematoxylin and eosin did not show any changes from what is considered normal.

The analysis of the injury zone (Th 8-9) of the traumatized animals showed macroscopically and microscopically large hemorrhagic necroses, particularly of the gray matter, with sparing of subpial white matter. Microscopically, in the hematoxylin-eosin stained sections there were losses of nerve cell bodies, axonal swellings and vacuolisation of remaining parts of the white matter. The cranial and caudal peri-injury zones (Th 7 and Th 10) appeared macroscopically normal. Microscopically, no complete necrosis of the tissue was displayed by the hematoxylin and eosin staining, but there were some condensed nerve cell bodies, small bleedings and vacuolization of the white matter.

\section{Immunohistochemistry}

We recorded in each animal the presence of expanded 'swollen' axons labeled with one of the three markers we used, ie $\beta$-APP (Figures 2-4), ubiquitin (Figures 5 and 6) and PGP 9.5. The results are presented in Table 4. No axonal swellings were seen in the hypothermic 


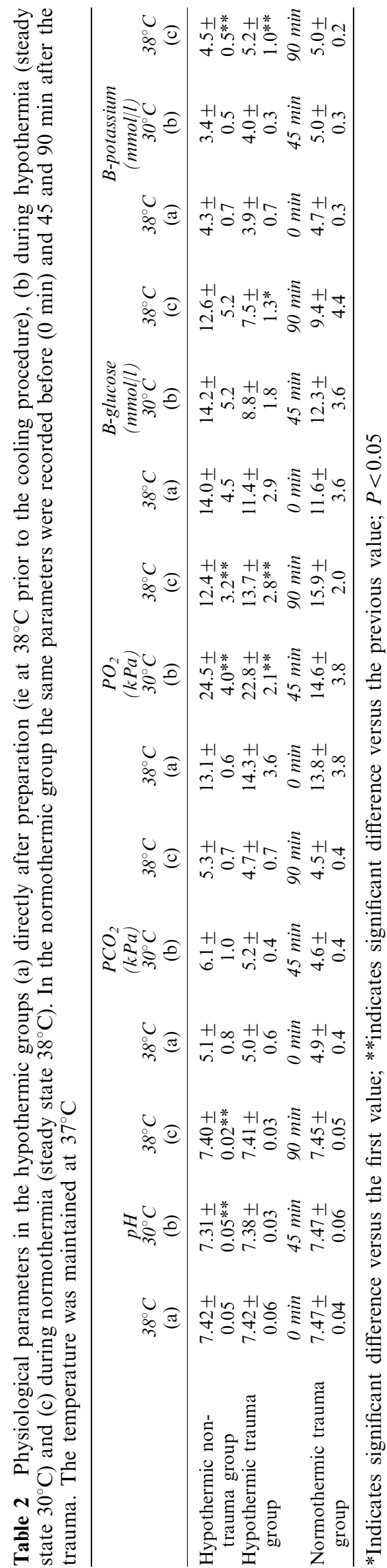

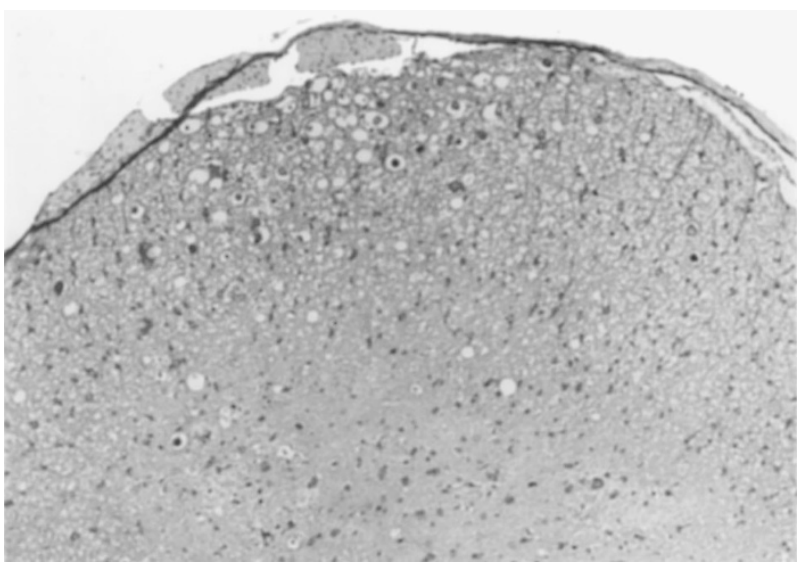

Figure 2 Low magnification of Figure 1 showing a wider area of the cord. Note the axons in the upper part of the figure indicated by arrows in Figure 1

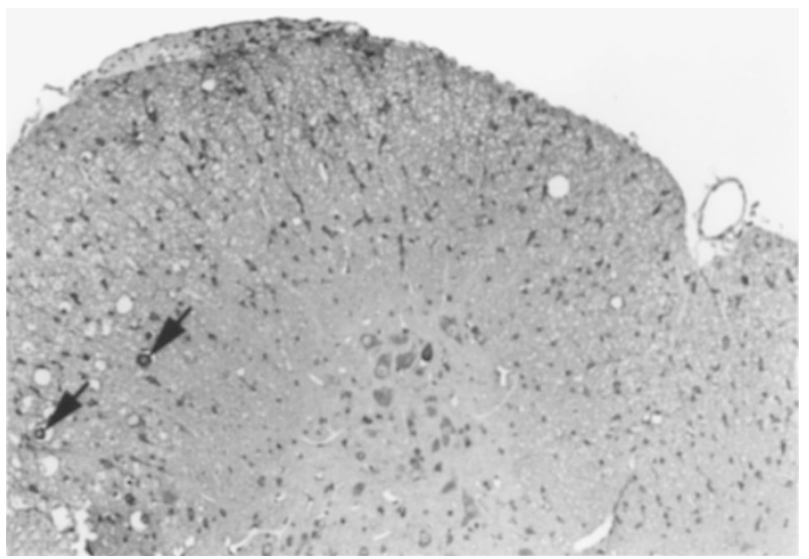

Figure 3 Rat with hypothermia and trauma. Only two abnormal $\beta$-APP containing axons are present. Compare with Figure 2

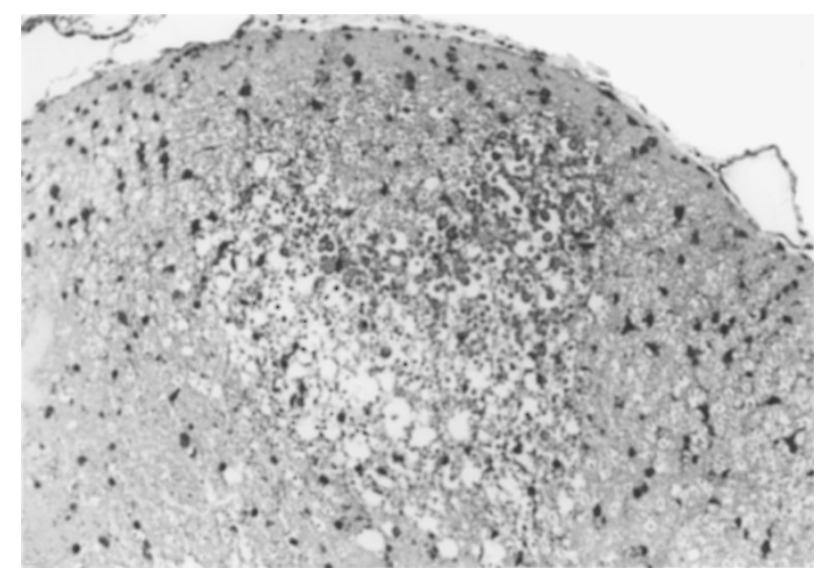

Figure 4 Ubiquitin immunostaining of a normothermic rat with trauma. There is a large collection of immunostained axons in the center 
Table 3 Mean cooling and rewarming times in the hypothermic groups 1 and 2. Mean temperatures for the steady state periods: In groups 1 and 2 (20 min hypothermia and 20 min normothermia); in group 3 (90 min normothermia)

\begin{tabular}{|c|c|c|c|c|}
\hline Group & $\begin{array}{l}\text { Mean cooling time } \\
38-30^{\circ} \mathrm{C} \text { ( min) }\end{array}$ & $\begin{array}{c}\text { Mean temperatures } \\
\text { during } 20 \text { min } \\
\text { hypothermia esophagus/ } \\
\text { spinal cord }\left({ }^{\circ} \mathrm{C}\right)\end{array}$ & $\begin{array}{c}\text { Mean rewarming time } \\
30-38^{\circ} \mathrm{C}(\mathrm{min})\end{array}$ & $\begin{array}{c}\text { Mean temperatures } \\
\text { during } 20 \text { min } \\
\text { normothermia esophagus/ } \\
\text { spinal cord }\left({ }^{\circ} \mathrm{C}\right)\end{array}$ \\
\hline $\begin{array}{l}\text { Hypothermic } \\
\text { non-trauma group }\end{array}$ & $28 \pm 5$ & $29.7 \pm 0.2 /-$ & $23 \pm 5$ & $38.3 \pm 0.3 /-$ \\
\hline $\begin{array}{l}\text { Hypothermic trauma } \\
\text { group }\end{array}$ & $25 \pm 2$ & $29.8 \pm 0.2 / 29.6 \pm 0.3$ & $23 \pm 3$ & $38.4 \pm 0.4 / 37.5 \pm 0.4^{*}$ \\
\hline $\begin{array}{l}\text { Normothermic trauma } \\
\text { group }\end{array}$ & - & - & - & $37.9 \pm 0.1 / 36.9 \pm 0.4^{*}$ \\
\hline
\end{tabular}

*Indicates significant difference between the recorded temperatures in the same group. $(P<0.05)$

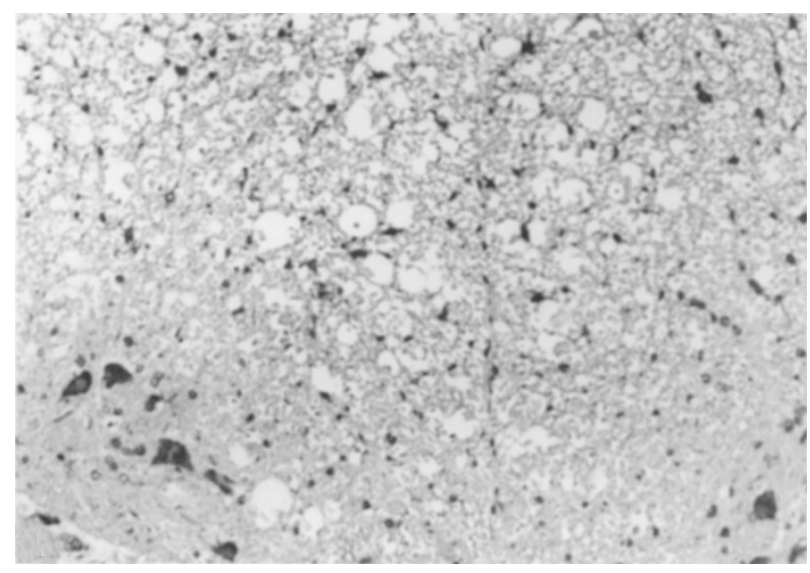

Figure 5 Ubiquitin immunostaining of a hypothermic rat with trauma. No abnormal axons are seen non-trauma group in any slide. In the normothermic trauma group axonal swellings were seen especially in the injury zone (Th $8-9$ ) and also more or less in the peri-injury zones (Th 7 and 10) of the longitudinal tracts.

In the hypothermic trauma group the number of axonal swellings was the same as in the normothermic trauma group in the injury zone (Th 8-9). However, in the cranial peri-injury-zones (Th 7) of the hypothermic trauma group, the number of axonal swellings was clearly less frequent, and was totally absent in some animals. The axonal swellings were also somewhat less frequent in the caudal peri-injury zones (Th 10), but the difference from the normothermic trauma group was not so clear-cut. No obvious difference was seen between the three different antibody methods used.

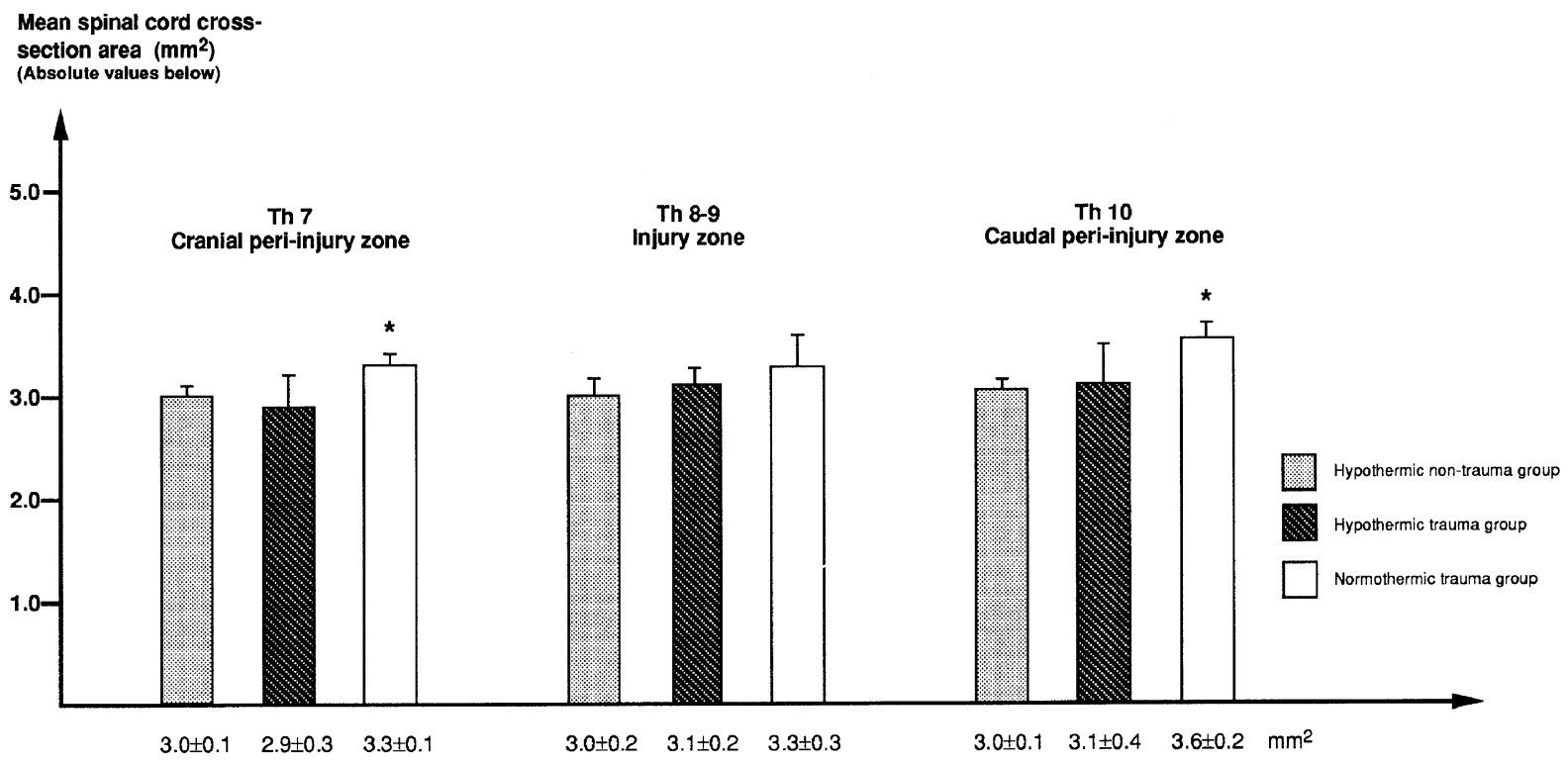

Figure 6 Cross-section areas of the spinal cord in the cranial peri-injury zone (Th 7$)$; the injury zone (Th $8-9)$ and in the caudal peri-injury zone (Th 10$)$. ${ }^{*}$ Indicates significant difference within the investigated zone. $P<0.05$ 
Table 4 Visual inspection of the immuno-labeled sections: $(-)=$ no swollen axons; $(+)=$ few swollen axons; $(++)=$ frequent swollen axons. The evaluation was made by two independent people in randomly taken slides from Th 7, 8-9 and 10

\begin{tabular}{lcccc}
\hline Animal & $\beta-A P P$ & Ubiquitin & PGP 9.5 \\
no. & Th7 Th8-9 Th10 & Th7 Th8-9 Th10 & Th7 Th8 -9 Th10 \\
\hline
\end{tabular}

Hypothermic non-trauma group

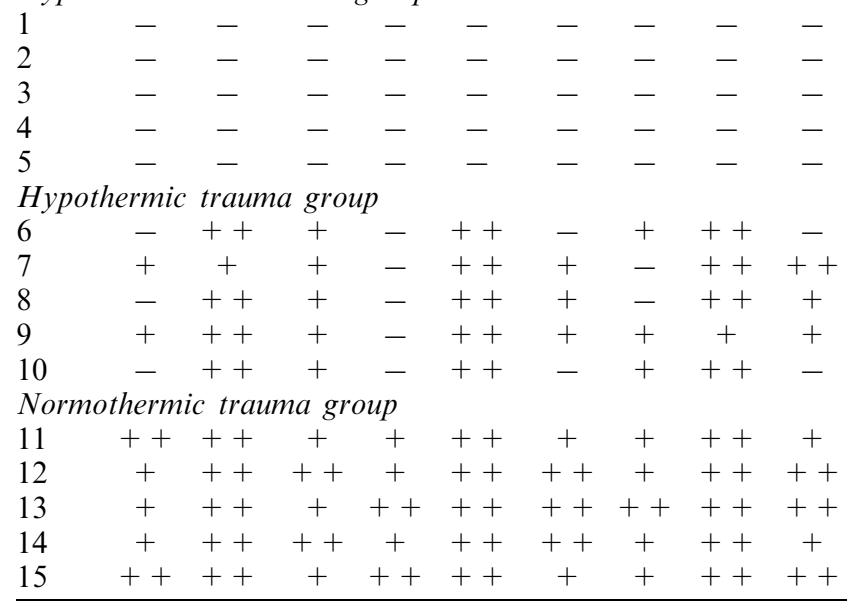

Spinal cord cross-section areas

The mean spinal cord cross-section areas were significantly larger in the peri-injury zones of the normothermic trauma group compared to the two hypothermic groups. This discrepancy, indicating a difference in the degree of spinal cord swelling, was not present in the injury zone.

\section{Discussion}

This study has shown a reduced number of immunolabeled, expanded axons in the peri-injury zones of animals sustained to hypothermic treatment as compared to normothermic injured animals. This difference was most obvious in the cranial peri-injury zones.

To identify the immuno-labeled expanded axons we used antibodies against $\beta$-APP, ubiquitin and PGP 9.5. $\beta$-APP is a membrane spanning glycoprotein, ${ }^{23}$ processed by the Golgi apparatus and carried along the axons by fast anterograde transport. ${ }^{42}$ Ubiquitin is a low-molecular-weight protein $(8 \mathrm{kDa})$ taking part in the non-lysosomal degrading of proteins within cells. ${ }^{24,25}$ PGP 9.5 is associated with the ubiquitin action. $^{26,27}$ The three proteins we used accumulate in injured axons and are therefore very useful modern markers of axonal pathology. ${ }^{21,26-28}$ In addition, all the compounds have important biological functions influencing remodeling of axons following trauma.

The ways by which hypothermia reduces the number of immuno-labeled expanded axons in our experiments are unknown. However, axons differ from other structures in the spinal cord in the sense that they are 'pipe-lines' passing the injury- and peri-injury zones. They can, therefore, be exposed to a number of pathophysiological mechanisms causing secondary lesions in, and in the vicinity of, the primary mechanical injury. The axons may, for instance be compressed as a result of increased swelling of the cord. Other factors, such as influences on the cytoskeleton, ${ }^{20}$ can result in impaired axonal transport of organelles and proteins which accumulate in the expanded axons, indicating axonal pathology. Reduced swelling of the cord and reduced influence of other secondary injury mechanisms may well be the reason why our injured hypothermic animals show fewer immuno-labeled expanded axons than injured normothermic rats.

Additional factors may well contribute to a reduced number of immuno-labeled expanded axons in the injured hypothermic rats. Thus, systemic hypothermia decreases the metabolic rate of the brain ${ }^{43}$ and reduces protein synthesis. ${ }^{44}$ Furthermore, axonal transport may be slowed down by hypothermia. ${ }^{45-47}$ Reduced axonal transport combined with diminished protein synthesis may well contribute to the reduced number of immuno-labeled expanded axons seen in the hypothermic injured rats.

The study presented in this paper thus indicates reduced axonal pathology in hypothermic injured rats compared with normothermic rats with the same degree of trauma. As stated, the animals derived from a previous methodological study where the primary intention was to study temperature differences. The fact that even a 20-min hypothermic period will evoke morphological alterations, demonstrates that several different hypothermic procedures must be evaluated to gain full understanding of the mechanisms behind the effects of hypothermic treatment. In our previous immunohistochemical studies using the same trauma model, and temperature management, we have demonstrated reduced edema formation $^{30}$ and glial activation ${ }^{29}$ in the traumatized hypothermic animals as compared to those randomized to trauma and normothermia. Taken together, all these immunohistochemical results indicate that systemic hypothermia reduces various pathophysiological mechanisms following spinal cord trauma which in normothermic rats with the same degree of trauma may lead to additional secondary injuries of the spinal cord.

In this study the temperature was recorded invasively in the spinal cord, and the cortico-spinal tracts were prone to damage by the probe. Therefore, we did not perform any evaluation of the motor function. To further investigate possible functional benefits of systemic hypothermia, studies including adequate functional outcome measures must be performed. Even if future experimental studies using systemic hypothermia as a treatment modality fail to show an improved neurological outcome, preservation of axons in the peri-injury zones may improve the 
prerequisites for methods promoting axonal regeneration.

\section{Acknowledgements}

We are grateful to Ms Madeleine Jarild and Ms Gunilla Tibbling for providing technical advice regarding immunohistochemistry. This study was supported by grants from the Laerdal Foundation, the Swedish Medical Research Council (project 12X-03020), the Swedish Association for the Neurologically Disabled, the Fredrik and Ingrid Thuring Foundation, the Tore Nilsson Foundation for Medical Research, the Åhlén Foundation and the Swedish Medical Society.

\section{References}

1 Holtz A. Early management after acute traumatic spinal cord injury. Upsala J Med Sci 1995; 100: $93-124$.

2 Tator $\mathrm{CH}$ et al. Neurological recovery, mortality and length of stay after acute spinal cord injury associated with changes in management. Paraplegia 1995; 33: 254-262.

3 Toscano J. Prevention of neurological deterioration before admission to a spinal cord injury unit. Paraplegia 1988; 26: $143-150$

4 Anderson DK, Hall ED. Pathophysiology of spinal cord trauma. Ann Emerg Med 1993; 22: 987-992.

5 Tator $\mathrm{CH}$. Update on the pathophysiology and pathology of acute spinal cord injury. Brain Pathol 1995; 5: 407-413.

6 Lipton S, Rosenberg P. Excitatory amino acids as a final common pathway for neurologic disorders. $N$ Engl $J$ Med 1994; 330: $613-622$.

7 Globus MY-T et al. Detection of free radical activity during transient global ischemia and recirculation: effects of intraischemic brain temperature modulation. $J$ Neurochem 1995; 65: $1250-1256$

8 Anthes D, Theriault E, Tator CH. Ultrastructural evidence for arteriolar vasospasm after spinal cord trauma. Neurosurgery 1996; 39: $804-814$.

$9 \mathrm{Li}$ GL et al. Apoptosis and expression of bcl-2 after compression trauma to rat spinal cord. J Neuropathol Exp Neurol 1996; 55: $280-289$.

10 Savitz SI, Rosenbaum DM. Apoptosis in neurological disease. Neurosurgery 1988; 42: 555-574.

11 Bignami A. Glial cells in the central nervous system. Discuss Neurosci 1991; 111: 9-44.

12 Norenberg MD. Astrocyte responses to CNS Injury. $J$ Neuropathol Exp Neurol 1994; 53: 213 -220.

13 Geisler F. Neuroprotection and regeneration of the spinal cord. In: Menezes A, Sonntag V (eds). Principles of spinal surgery. Vol 2. McGraw-Hill, New York 1996, pp 769-784.

14 Bracken $\mathrm{M}$ et al. Administration of methylprednisolone for 24 or 48 hours or Tirilazad Mesylate for 48 hours in the treatment of Acute Spinal Cord Injury. Results of the Third National Acute Spinal Cord Injury Randomized Controlled Trial. JAMA 1997; 277: $1597-1604$.

15 Kapfhammer JP. Axon sprouting in the spinal cord: growth promoting and growth inhibitory mechanisms. Anat Embryol (Berl) 1997; 196: $417-426$.

16 Schwab ME, Brösalme C. Regeneration of lesioned corticospinal tract fibers in the adult rat spinal cord under experimental conditions. Spinal cord 1997; 35: 469-473.

17 Tator $\mathrm{CH}$. Biology of neurological recovery and functional restoration after spinal cord injury. Neurosurgery 1998; 42: $696-$ 708.

18 Bernstein JJ, Goldberg WJ. Experimental spinal cord transplantation as mechanism of spinal cord regeneration. Paraplegia 1995; 33: $250-253$.
19 Olsson L et al. On CNS repair and protection strategies: novel approaches with implications for spinal cord injury and Parkinson's disease. Brain Res Rev 1998; 26: $302-305$.

20 Maxwell WL, Povlishock JT, Graham DL. A mechanistic analysis of non-disruptive axonal injury: a review. $J$ Neurotraum 1997; 14: $419-440$.

21 Li GL, Farooque M, Holtz A, Olsson Y. Changes of $\beta$-amyloid precursor protein after compression trauma to the spinal cord: An experimental study in the rat. $J$ Neurotraum 1995; 12: 269 277.

22 Strich SJ. The pathology of brain damage due to blunt head injuries. In: Walter AE, Critchley M (eds). The late effects of head injury. Charles C Thomas: Springfield 1970, pp 501-524.

23 Gentleman SM et al. $\beta$-amyloid precursor protein ( $\beta$-APP) as a marker of axonal injury after head injury. Neurosci lett 1993; 160: $139-144$.

24 Ciehanover A. The ubiquitin-mediated proteolytic pathway. Brain Pathol 1993; 3: 67-75.

25 Hershsko A. The ubiquitin pathway for protein degradation. Trends Biochem Sci 1991; 16: 265 -268.

26 Anderson VER et al. Ubiquitin, PGP 9.5 and dense body formation intrimethylin intoxication: differential neuronal responses to chemically induced cell damage. Appl Neurobiol 1992; 18: $360-375$

27 Lowe $\mathbf{J}$ et al. Ubiquitin carboxyl-terminal hydrolase (PGP 9.5) is selectively present in ubiquitiated inclusion bodies characteristic of human neurodegenerative diseases. J Pathol 1990; 161: 153 160 .

$28 \mathrm{Li}$ GL, Farooque M, Holtz A, Olsson Y. Expression of the ubiquitin carboxyl-terminal hydrolase PGP 9.5 in axons following spinal cord compression trauma. An immunohistochemical study in the rat. APMIS 1997; 105: $384-390$.

$29 \mathrm{Yu}$ WR et al. Systemic hypothermia following spinal cord compression injury in the rat. An immunohistochemical study on the expression of vimentin and GFAP. Neuropathologica 1999; 19: $172-180$

$30 \mathrm{Yu}$ WR et al. Systemic hypothermia following spinal cord compression injury in the rat. Reduction of plasma protein extravasation demonstrated by immunohistochemistry. Acta Neuropathol 1999; 98: 15-21.

31 Robertson CS, Foltz R, Grossman RG, Goodman JC. Protection against experimental ischemic spinal cord injury. $J$ Neurosurg 1986; 64: $633-642$.

32 Marsala M, Vanicky I, Yaksh TL. Effect of graded hypothermia (27 degrees to 34 degrees $\mathrm{C}$ ) on behavioral function, histopathology, and spinal blood flow after spinal ischemia in rat. Stroke 1994; 25: 2038 - 2046.

33 Martinez-Arizala A, Green BA. Hypothermia in spinal cord injury. J Neurotraum 1992; 9: S497-S505.

34 Clifton GL. Systemic hypothermia in treatment of severe brain injury. J Neurosurg Anesthesiol 1995; 7: $152-156$.

35 Marion $\mathrm{D}$ et al. Treatment of traumatic brain injury with moderate hypothermia. N Engl J Med 1997; 336: 540-546.

36 Westergren $\mathrm{H}$ et al. Systemic hypothermia following spinal cord compression injury in the rat. Does recorded temperature in accessible organs reflect the temperature in the spinal cord? $J$ Neurotraum 1998; 15: $943-954$.

37 Holtz A, Nyström B, Gerdin B. Spinal cord blood-flow measured by ${ }^{14} \mathrm{C}$-Iodoantipyrine autoradiography during and after graded spinal cord compression in rats. Surg Neurol 1989; 31: 350-360.

$38 \mathrm{Li} \mathrm{GL}$, Farooque M. Expression of ubiquitin-like immunoreactivity in axons after compression trauma to the rat spinal cord. Acta Neuropathol 1996; 91: 155- 160.

39 Itoh $\mathrm{K}$ et al. Application of coupled oxidation reaction to electron microscopic demonstration of horseradish peroxidase: cobalt glucose oxidase method. Brain Res 1979; 175: $341-346$.

40 Hancock MB. Visualization of peptide immunoreactive processes of serotonin-immunoreactive cells using two color immunoperoxidase staining. J Histochem Cytochem 1984; 32: $311-314$

41 Shu S, Ju G, Fan L. The glucose oxidase-DAB-nickel method in peroxidase histochemistry of the nervous system. Neurosci Lett 1988; 85: $169-171$ 
42 Koo EH et al. Precursor of amyloid protein in Alzheimer's disease undergoes fast anterograde axonal transport. Proc Natl Acad Sci USA 1990; 87: 1561-1565.

43 Michenfelder JD, Milde JH. The relationship among canine brain temperature, metabolism, and function during hypothermia. Anesthesiology 1991; 75: 130-136.

44 Kamme F, Wielock T. The effect of hypothermia on protein synthesis and the expression of immediate early genes following transient cerebral ischemia. In: Siesjö and Wielock (eds). Advances in Neurology vol 71; Cellular and Molecular Mechanisms in Ischemic Brain Damage. Philadelphia: Lippincott and Revan Publishers 1996, pp 199-206.
45 Whiteley SJ, Townsend J, Tomlinson DR, Brown AM. Fast orthograde axonal transport in sciatic motorneurones and nerve temperature in streptozotocin-diabetic rats. Diabetologia 1985; 28: $847-851$.

46 Padilla S, Lyerly D. Effects of hypothermia on the in vivo measurement of rapid axonal transport in the rat: a cautionary noete. J Neurochem 1986; 46: 1227-1230.

47 Boyes WK, Padilla S, Dyer RS. Body temperature-dependent and independent actions of chlordimeform on visual evoked potentials and axonal transport in optic system of rat. Neuropharmacology 1985; 24: $743-749$. 